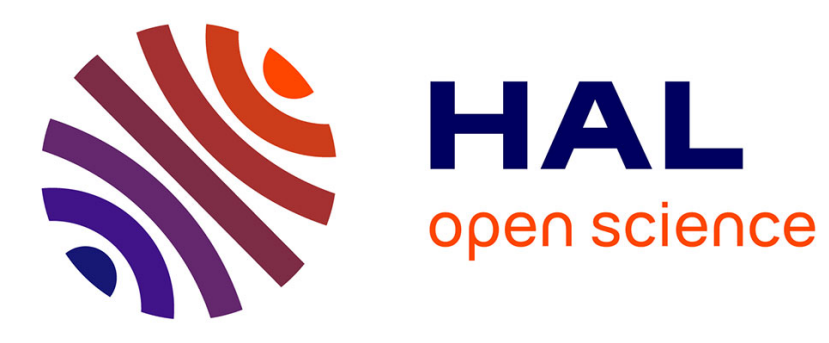

\title{
Spring-Mass Behavior during Exhaustive Run at Constant Velocity in Elite Triathletes
}

Giuseppe Rabita, Jean Slawinski, Olivier Girard, Frank Bignet, Christophe Hausswirth

\section{- To cite this version:}

Giuseppe Rabita, Jean Slawinski, Olivier Girard, Frank Bignet, Christophe Hausswirth. Spring-Mass Behavior during Exhaustive Run at Constant Velocity in Elite Triathletes. Medicine and Science in Sports and Exercise, 2011, 43, pp.685 - 692. 10.1249/MSS.0b013e3181fb3793 . hal-01561309

\section{HAL Id: hal-01561309 https: / hal-insep.archives-ouvertes.fr/hal-01561309}

Submitted on 18 Jul 2017

HAL is a multi-disciplinary open access archive for the deposit and dissemination of scientific research documents, whether they are published or not. The documents may come from teaching and research institutions in France or abroad, or from public or private research centers.
L'archive ouverte pluridisciplinaire HAL, est destinée au dépôt et à la diffusion de documents scientifiques de niveau recherche, publiés ou non, émanant des établissements d'enseignement et de recherche français ou étrangers, des laboratoires publics ou privés. 


\title{
Spring-Mass Behavior during Exhaustive Run at Constant Velocity in Elite Triathletes
}

\author{
GIUSEPPE RABITA ${ }^{1}$, JEAN SLAWINSKI ${ }^{1,2}$, OLIVIER GIRARD ${ }^{3}$, FRANK BIGNET ${ }^{4}$, \\ and CHRISTOPHE HAUSSWIRTH ${ }^{1}$ \\ ${ }^{I}$ Research Department, National Institute of Sport, Expertise and Performance, INSEP, Paris, FRANCE; \\ ${ }^{2}$ Team Lagardère, Stade Paris Jean-Bouin, Paris, FRANCE; ${ }^{3}$ ASPETAR, Research and Education Center, Doha, QATAR; \\ and ${ }^{4}$ French Federation of Triathlon, La Plaine Saint-Denis, FRANCE
}

\begin{abstract}
RABITA, G., J. SLAWINSKI, O. GIRARD, F. BIGNET, and C. HAUSSWIRTH. Spring - Mass Behavior during Exhaustive Run at Constant Velocity in Elite Triathletes. Med. Sci. Sports Exerc., Vol. 43, No. 4, pp. 685 - 692, 2011. Purpose: The aims of this study were i) to evaluate changes in leg-spring behavior during an exhaustive run in elite triathletes and ii) to determine whether these modifications were related to an increase in the energy cost of running $\left(C_{r}\right)$. Methods: Nine elite triathletes ran to exhaustion on an indoor track at a constant velocity corresponding to $95 \%$ of the velocity associated with the maximal oxygen uptake (mean T SD $=5.1 \mathrm{~T} 0.3 \mathrm{mIS}{ }^{\mathrm{j} 1}$, time to exhaustion $=10.7$ T $2.6 \mathrm{~min})$. Vertical and horizontal ground reaction forces were measured every lap $(200 \mathrm{~m})$ by a 5 -m-long force platform system. $C_{r}$ was measured from pulmonary gas exchange using a breath-by-breath portable gas analyzer. Results: Leg stiffness (j13.1\%, $P$ G 0.05 ) and peak vertical (j9.2\%, $P$ G 0.05 ) and propulsive $(\mathrm{j} 7.5 \%, P \mathrm{G} 0.001)$ forces decreased significantly with fatigue, whereas vertical stiffness did not change significantly. Leg and vertical stiffness changes were positively related with modifications of aerial time $\left(R^{2}=0.66, P \mathrm{G} 0.01\right.$ and $R^{2}=0.72, P \mathrm{G} 0.01$, respectively $)$ and negatively with contact time $\left(R^{2}=0.71, P \mathrm{G} 0.01\right.$ and $R^{2}=0.74, P \mathrm{G} 0.01$, respectively). Alterations of vertical forces were related with the decrease of the angle of velocity vector at toe off $\left(R^{2}=0.73, P \mathrm{G} 0.01\right)$. When considering mean values of oxygen uptake, no change was observed from $33 \%$ to $100 \%$ of the time to exhaustion. However, between one-third and two-thirds of the fatiguing run, negative correlations were observed between oxygen consumption and leg stiffness $\left(R^{2}=0.83, P \mathrm{G} 0.001\right)$ or vertical stiffness $\left(R^{2}=0.50, P \mathrm{G} 0.03\right)$. Conclusions: During a constant run to exhaustion, the fatigue induces a stiffness adaptation that modifies the stride mechanical parameters and especially decreases the maximal vertical force. This response to fatigue involves greater energy consumption. Key Words: MUSCULOSKELETAL STIFFNESS, RUNNING, FATIGUE, ENERGY COST, TRIATHLON
\end{abstract}

$\mathrm{M}$ any studies have attempted to identify factors involved in performance of elite triathletes by analyzing biomechanical parameters with exercise duration during triathlon $(3,18)$. Although swimming and cycling have both energetic $(11,26)$ and mechanical $(9,12)$ influences on the subsequent mode(s) of locomotion, triathlon overall finishing position is strongly determined by running performance (38). Consequently, a better understanding of the effects of running fatigue as it influences mechanical modification and metabolic energy costs in triathletes continues to be a challenge to improve training programs.

In humans, many studies have been carried out to characterize running using the spring - mass model (SMM) $(4,6,27)$. This model consists of a point mass bouncing on

Address for correspondence: Giuseppe Rabita, Ph.D., Research Department, National Institute of Sport, Expertise and Performance, 11 Avenue du Tremblay, 75012, Paris, France; E-mail: giuseppe.rabita@insep.fr.

Submitted for publication March 2010.

Accepted for publication September 2010. a massless spring. SMM provides a well-accepted theoretical basis from which leg stiffness $\left(k_{\mathrm{leg}}\right.$, ratio of the vertical ground reaction force to the leg-spring compression at middle of the stance phase) and vertical stiffness ( $k_{\text {vert }}$, ratio of the maximal force to the vertical downward maximal displacement of the center of mass (COM)) can be determined. These types of mechanical stiffness have been frequently used for characterization of running mechanics because they influence the regulation of temporal and kinematic variables $(14,30)$.

Numerous studies specifically analyzed the changes in biomechanical parameters during running in fatigue conditions $(2,7,25,35)$, although only few explored the evolution of leg stiffness and its relationships with step temporal variables. Furthermore, the results have been quite contradictory. For constant and moderate running intensities (under the lactic threshold), Dutto and Smith (13) showed that $k_{\text {leg }}$ and $k_{\text {vert }}$ both decreased with fatigue, whereas Hunter and Smith (22) reported no significant change. Both studies, however, reported that stride frequency was more strongly related to $k_{\text {vert }}$ than $k_{\text {leg. }}$. For severe running intensities (above the lactic threshold), Slawinski et al. (35) did not detect any variation of $k_{\text {leg }}$ or $k_{\text {vert }}$ before or after a 2000-m maximal run. In contrast, Girard et al. (16) found a decrease of $k_{\text {vert }}$ while $k_{\text {leg }}$ remained constant during a self-paced 5000-m run. For sprint running intensities, the 
fatigue-induced changes in mechanical stiffness were concluded to be mainly due to modifications in the COM vertical displacement rather than changes in the maximal force; furthermore, it appeared that $k_{\text {vert }}$ was more affected by the fatigue state than $k_{\text {leg }}(20,29)$. Nevertheless, neither severe nor sprint studies imposed a constant pace for the run, although temporal, kinematic, and kinetic parameters associated with the spring - mass stiffness had been shown to be directly dependent on the running speed $(1,6,27)$.

To our knowledge, changes in spring - mass behavior on the energy cost of running $\left(C_{r}\right)$ at constant velocity have only been investigated for moderate intensities (19). The authors did not find a clear relationship between energy cost of running and changes in frequency or stiffness. However,

other studies showed that $\boldsymbol{k}_{\operatorname{leg}}$ and/or $\boldsymbol{k}_{\text {vert }}$ are among those biomechanical parameters that exhibit the strongest associa-

tion to the $C_{r}(7,10,19,23,28,35)$.

The aims of this study were, therefore, to characterize changes in leg-spring behavior in elite triathletes during a constant velocity exhaustive run and to verify whether these

modifications were related to the increase in the energy cost of running. On the basis of consideration of the literature, we hypothesized that i) $k_{\text {leg }}$ and $k_{\text {vert }}$ would decrease during the run, and ii) these decreases would be inversely related with the changes in maximal oxygen uptake.

\section{METHODS}

\section{Subjects}

Nine elite triathletes belonging to the French National Team, including six men (mean T SD: age $=23.2 \mathrm{~T} 3.2 \mathrm{yr}$, height $=181.7 \mathrm{~T} 2.4 \mathrm{~cm}$, weight $=68.3 \mathrm{~T} 5.4 \mathrm{~kg}$ ) and three women (age $=25.0 \mathrm{~T} 4.4 \mathrm{yr}$, height $=166.7 \mathrm{~T} 4.2 \mathrm{~cm}$, weight $=58.3 \mathrm{~T} 3.2 \mathrm{~kg}$ ), were recruited to participate in the study. All of these athletes had competed at international level during the year. Throughout this year, the range of training distances per week was approximately $20-25 \mathrm{~km}$ in swimming, $200-350 \mathrm{~km}$ in cycling, and $55-75 \mathrm{~km}$ in running. Procedures were explained to each subject before participation. Written informed consent was obtained from each of the subjects, and the study was conducted according to the Declaration of Helsinki. This study was approved by the local ethics committee before its initiation.

\section{Procedures}

Two runs on an indoor 200-m synthetic track were required of each subject. The first run was carried out as a graded exercise test (3-min stages) to determine maximal oxygen uptake $\left(V \mathrm{O}_{2 \max }\right)$ and its associated velocity $\left(\mathrm{vV} \mathrm{O}_{2 \max }\right)$. The second run, performed $2 \mathrm{~d}$ later, was a constant velocity run performed until exhaustion at a speed corresponding to $95 \%$ of $\mathrm{vV} \mathrm{O}_{2 \max }$. Throughout the tests, the subjects adopted the required velocity by using an audio rhythm that gave the time allotted to cover $20 \mathrm{~m}$; visual marks had been set at 20-m intervals along the track.

\section{Data Collection}

Ground reaction force. Once per lap during the constant run to exhaustion, the vertical and horizontal components of the ground reaction forces were measured by a 5-m-long force platform system (natural frequency Q $500 \mathrm{~Hz}$ ). The system consisted of five individual force plates $(1.00 \times 1.00 \mathrm{~m})$ connected in series, covered with a tartan mat, and leveled with the stadium track. It allowed recording ground reaction force of two or three steps per lap (according to the step length and the separated distance of the first foot contact from the entrance of the force plate area). Each force platform was equipped with Kistler piezoelectric sensors (KI 9067; Kistler, Wintertur, Switzerland). The force signals were sampled at $500 \mathrm{~Hz}$.

$\dot{\mathrm{VO}}_{2}$ response. Values of oxygen uptake were determined breath by breath during both the incremental test and the constant run to exhaustion (Cosmed $\mathrm{K} 4 \mathrm{~b}^{2}$, Rome, Italy). Gas analyzer was calibrated before each test using ambient air $\left(\mathrm{O}_{2}=20.93 \%\right.$ and $\left.\mathrm{CO}_{2}=0.03 \%\right)$ and a gas mixture of known composition $\left(\mathrm{O}_{2}=16.0 \%\right.$ and $\left.\mathrm{CO}_{2}=5.0 \%\right)$. An $\mathrm{O}_{2}$ analyzer with a polarographic electrode and a $\mathrm{CO}_{2}$ analyzer with an infrared electrode sampled orally expired gases. The facemask, presenting a low dead space $(70 \mathrm{~mL})$, was equipped with a low-resistance, bidirectional digital turbine (28-mm diameter). This turbine was calibrated before each test with a 3-L syringe (Hans Rudolph Inc., Dallas, TX).

\section{Data Analyses}

Spatiotemporal parameters. A typical example of changes in vertical $\left(F_{z}\right)$ and horizontal $\left(F_{y}\right)$ components of ground reaction force are presented in Figure 1. Contact and aerial phases (i.e., contact time, $t_{c}(\mathrm{~s})$, and aerial time, $\left.t_{a}(\mathrm{~s})\right)$ were defined when the vertical force was more than and less than $50 \mathrm{~N}$, respectively. Active peak amplitude of vertical force $\left(F_{z \max }\right)$, peak braking $\left(F_{y \min }\right)$ and pushoff $\left(F_{y \max }\right)$ forces, step frequency $\left(f=\left(t_{a}+t_{c}\right)^{\mathrm{j} 1}\right.$, in hertz), and step length (SL $=V_{\text {forward }} f^{\mathrm{j} 1}$, in meters) were also determined. Anteroposterior forces were used to determine

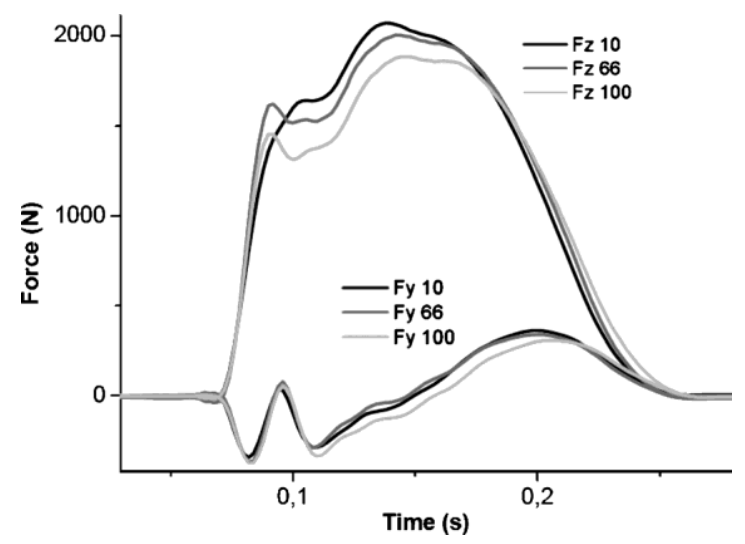

FIGURE 1-Typical example of changes in vertical $\left(F_{z}\right)$ and horizontal $\left(F_{y}\right)$ reaction force components measured at the beginning $(10 \%)$, at the second-third $(66 \%)$, and at the end $(100 \%)$ of the exhaustive run. 
the braking and push-off phases during ground contact when the anteroposterior force was negative and positive, respectively. Braking and push-off impulse $\left(B_{\text {imp }}\right.$ and $P_{\text {imp }}$, respectively) values were determined from the product of the effective force applied to the running surface and foot - ground contact times of these respective phases. Force data were then used for calculating leg-spring behavior parameters.

SMM characteristics. Leg and vertical stiffness dur-

ing running was calculated using a classical method $(14,27)$. Leg stiffness $\left(k_{\operatorname{leg}}, \mathrm{kNIm}^{\mathrm{j} 1}\right)$ was defined as follows:

$$
k_{\operatorname{leg}} 1 / 4 F_{z \max }=\$ L
$$

where $F_{z \max }$ was the maximal vertical ground reaction force and $\$ L$ was the leg compression at the middle of the stance phase, that is, when $F$ was maximal and the leg was maximally compressed. $\$ L$ was calculated from the maximal vertical displacement of the COM, $\$ y$, the initial length of the leg spring, $L_{0}$ (vertical distance from the ground to the greater trochanter during standing), and half of the angle swept by the leg spring during the contact phase, 5 :

$$
\$ L^{1 / 4} \$ y \mathrm{p} L_{0} \text { ठ } 1-\cos \oplus
$$

The vertical displacement $\$ y$ was calculated by integrating the vertical acceleration twice (constants of integration were calculated according to the methodology proposed by Cavagna (8)). 5 was calculated from the contact time $\left(t_{c}\right)$, the forward speed $(u)$, and the $L_{0}$, according to the following formula:

$$
O / 4 \sin ^{-1} \partial u t_{c}=2 L_{0} \mathrm{P}
$$

where $u t_{c}$ represented the horizontal distance traveled by the COM (in meters) during the contact phase.

The vertical stiffness $\left(k_{\mathrm{vert}}, \mathrm{kNIm}^{\mathrm{j} 1}\right)$ was defined by the following equation:

$$
k_{\text {vert }} 1 / 4 \quad F_{\text {zmax }}=\$ y
$$

The angle ( $>$, in degrees) of the velocity vector of the $\mathrm{COM}$ at toe off was calculated as:

$$
\tan ठ>\mathrm{P} \quad 1 / 4 \quad V_{z}=V_{y}
$$

where $V_{z}$ and $V_{y}$ represented the vertical and the horizontal velocities of the COM at toe off. Both were calculated using integration against time of the vertical and horizontal acceleration of the COM (8).

For every parameter, the average of two laps (i.e., four to six steps) around one-tenth, one-third, and two-thirds of the time to exhaustion were calculated and averaged. The values corresponding to the end of the run were calculated from the data of the two last laps. Then, the measures were effectively recorded at $9.4 \% \mathrm{~T} 0.8 \%, 33.4 \% \mathrm{~T} 1.0 \%, 66.1 \% \mathrm{~T} 1.1 \%$, and $95.3 \% \mathrm{~T} 0.9 \%$ of the time to exhaustion. To simplify, these times were noted $10 \%, 33 \%, 67 \%$, and $100 \%$. The values were normalized with respect to those obtained at the beginning (one-tenth) of the run to exhaustion.

Energy cost of running. The breath-by-breath $V \mathrm{O}_{2}$ data were fitted to a single-exponential function (36).
According to Gaesser and Poole (15), a first steady state of oxygen uptake could be reached after 3 min of exercise during a constant velocity run performed at a severe intensity. Thus, $V \mathrm{O}_{2}$ changes were normalized with respect to the values obtained at $33 \%$ of the time to exhaustion. Then, the $C_{r}\left(\mathrm{JIkg}^{\mathrm{j} 1} \mathrm{Im}^{\mathrm{j} 1}\right)$ was calculated as

$$
C_{r} 1 / 4 \vee \mathrm{O}_{2} E_{\mathrm{O}_{2}} V^{-}{ }_{1}^{-}
$$

$$
{ }_{95} M
$$

where $\sqrt{ } \mathrm{O}_{2}$ was the oxygen uptake $\left(\mathrm{mL} \mathrm{O} \mathrm{O}_{2} \mathrm{Im}^{\mathrm{j} 1}\right), E_{\mathrm{O}}$ (21.3 JImL O${ }_{2}^{-1}$ ) was the energy equivalent of $1 \mathrm{~mL} \mathrm{O}_{2}$ for a respiratory exchange ratio of $1, V_{95}$ was the velocity $\left(\mathrm{mImin}^{\mathrm{j} 1}\right.$ ) during the run to exhaustion, and $M$ was the body mass (kg).

\section{Statistical Analysis}

For all tested parameters, the effect of fatigue was determined by a single factor ANOVA for repeated measures (33\%, 66\%, and $100 \%$ of the time to exhaustion). When a significant main effect was observed, the post hoc Sheffe test was performed. Pearson' s correlation coefficients were used to examine the relationships between leg-spring stiffness
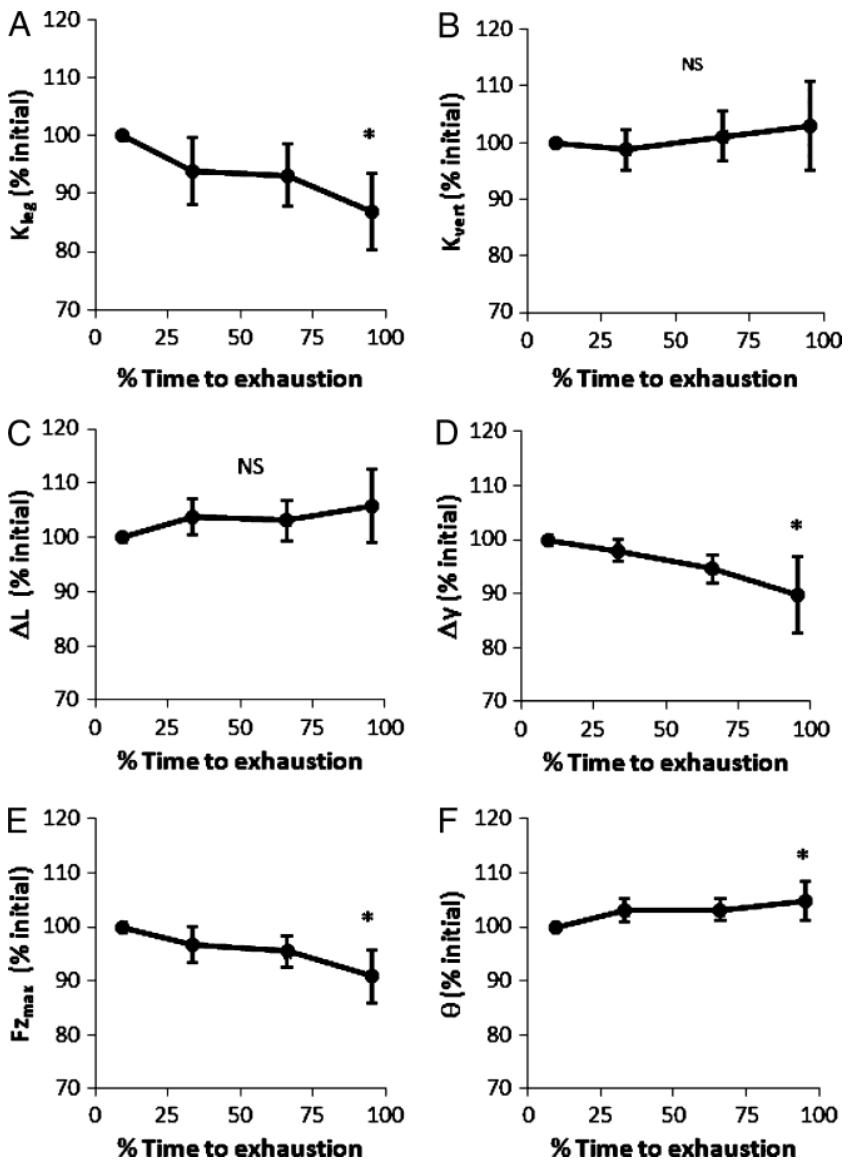

FIGURE 2-Evolution of the mean normalized values T SD in (A) leg stiffness $\left(k_{\text {leg }}\right),(B)$ vertical stiffness $\left(k_{\text {vert }}\right),(C)$ leg compression (\$L), (D) vertical displacement of the COM $(\$ y)$, (E) vertical component of reaction force $\left(F_{z \max }\right)$, and $(\mathrm{F})$ angle of the spring leg at touchdown (5). Data were normalized and expressed as the percentage of the values obtained at $10 \%$ of the time to exhaustion. *Significant difference at $P \mathrm{G} 0.05$. 
$\left(k_{\text {leg }}\right.$ and $\left.k_{\text {vert }}\right), C_{r}$, and spatiotemporal parameters. Values have been presented as mean T SD. All statistical analyzes were conducted at $P \mathrm{G} 0.05$.

\section{RESULTS}

During the incremental test, $\sqrt{ } \mathrm{O}_{2} \max$ and $\mathrm{v} \cdot \mathrm{O}_{2} \max$ mean values were equal to $71.5 \mathrm{~T} 6.5 \mathrm{mLIkg}{ }^{\mathrm{j} 1} \mathrm{Imin}^{\mathrm{j} 1}$ and $5.1 \mathrm{~T} 0.3) \mathrm{mIs}^{\mathrm{j} 1}$, respectively. During the second test, the mean time to exhaustion was 10.7 T $2.6 \mathrm{~min}$, which corresponded to a mean distance of $3258 \mathrm{~T} 819 \mathrm{~m}$ or $16.3 \mathrm{~T} 4.1$ laps. During the interval $33 \%-100 \%$ of the time to exhaustion, - $\mathrm{O}_{2}$ values, from $65.1 \mathrm{~T} 3.9$ to $63.6 \mathrm{~T} 4.1 \mathrm{mLIkg}^{\mathrm{j} 1} \mathrm{Imin}^{\mathrm{j} 1}$, did not change significantly ( $P 90.05)$.

Leg stiffness decreased by $13.1 \%$ with exhaustion $(P=0.01$; Fig. 2A). The maximal vertical force during contact $\left(F_{z \max }\right)$ decreased significantly with fatigue (j9.2\%; Fig. 2E), whereas the change in leg-spring compression $(\$ L)$ was not significant (Fig. 2C). The vertical stiffness did not show any significant change (P 9 0.05; Fig. 2B). Indeed, $\$ y$ decreased proportionally with $F_{z \max }$ (Fig. 2D). All absolute mean values are presented in Table 1.
The normalized changes and raw mean values of the temporal and kinematic parameters are presented in Table 1. A slight but significant increase in the step frequency $(P G 0.05)$ was observed despite a significant increase in the contact time (+4.3\%, $P$ G 0.05). This result was explained by a greater decrease in the aerial time. The step length decreased significantly ( $P$ G 0.05$)$. The horizontal distance traveled by the COM during the contact phases increased. Braking and propulsive impulse did not change significantly ( $P 90.05)$. Contrary to the normalized values of $F_{y \min }$ (i.e., the maximal braking anteroposterior force), a significant decrease was observed for $F_{\text {ymax }}(P$ G 0.001; Table 1). The angle of the velocity vector at takeoff significantly decreased (j18.3\%).

The relationships between $k_{\text {leg }}, k_{\text {vert }}$, and $F_{\text {zmax }}$ versus selected temporal, kinematic, and dynamic parameters are presented in Table 2, whereas the significant relationships have been included in Figures $3 \mathrm{~A}-\mathrm{E}$. The relationships between normalized changes in horizontal impulses were found to be significantly related with $5(R=0.54, P=0.021$ for $B_{\text {imp }}$ and $R=0.53, P=0.022$ for $P_{\text {imp }}$ ) but not with minimal or maximal $F_{\text {ymin }}$ or $F_{y \max }$ changes.

TABLE 1. Evolution of spatiotemporal and horizontal dynamic parameters.

\begin{tabular}{|c|c|c|c|c|c|}
\hline & $10 \%$ & $33 \%$ & $67 \%$ & $100 \%$ & $P$ \\
\hline \multicolumn{6}{|l|}{ Normalized data (\%) } \\
\hline \multicolumn{6}{|c|}{ Normalized spatiotemporal parameters } \\
\hline$t_{c}$ & - & $102.6(3.9)$ & $102.8(3.7)$ & $104.3(6.3)^{*}$ & 0.031 \\
\hline$t_{a}$ & - & $97.6(5.7)$ & $94.5(6.3)^{*}$ & $92.1(7.7)^{* *} \dagger$ & 0.010 \\
\hline$f_{\text {step }}$ & - & 99.6 (1.9) & $101.0(2.4)$ & $101.3(2.2)^{*} \dagger$ & 0.048 \\
\hline$L_{\text {step }}$ & - & $99.4(1.6)$ & $99.1(1.2)$ & $97.7(1.8)^{* *} \dagger$ & 0.001 \\
\hline$>$ & - & $93.3(12.1)$ & $88.9(8.9)^{*}$ & $81.7(11.2)^{* * *} \dagger$ & G0.001 \\
\hline \multicolumn{6}{|c|}{ Normalized horizontal dynamic parameters } \\
\hline$F_{y \min }$ & - & $99.8(11.3)$ & $97.0(9.2)$ & $97.1(8.0)$ & ns \\
\hline$B_{\text {imp }}$ & - & $102.6(4.8)$ & $100.0(4.6)$ & $98.9(4.1)$ & ns \\
\hline$F_{y \max }$ & - & $97.6(4.0)$ & $94.3(4.2)^{* *}$ & $92.5(2.1)^{* * *} \dagger \dagger$ & 0.001 \\
\hline$P_{\mathrm{imp}}$ & - & $102.1(4.8)$ & $99.5(4.6)$ & $98.6(5.0)$ & ns \\
\hline \multicolumn{6}{|c|}{ Normalized energy parameters } \\
\hline$\dot{\mathrm{V}}_{2}$ & & - & $100.5(4.2)$ & $97.7(4.4)$ & ns \\
\hline$C_{r}$ & & - & $100.5(4.2)$ & $97.7(4.4)$ & ns \\
\hline \multicolumn{6}{|l|}{ Raw data } \\
\hline \multicolumn{6}{|l|}{ Stiffness parameters } \\
\hline$k_{\text {leg }}\left(\mathrm{kNIm}{ }^{\mathrm{j} 1}\right)$ & $11.7(1.9)$ & $10.9(1.3)$ & $10.8(1.2)$ & $10.4(1.0)^{*}$ & 0.012 \\
\hline$k_{\text {vert }}\left(\mathrm{kNIm}^{\mathrm{j} 1}\right)$ & $44.4(7.2)$ & $43.6(6.3)$ & $44.5(5.2)$ & $45.0(5.3)$ & ns \\
\hline$F_{z \max }(\mathrm{N})$ & $1963(262)$ & $1893(235)$ & 1864 (192) & $1772(219)^{*}$ & 0.018 \\
\hline$\$ L(\mathrm{~m})$ & $0.168(0.016)$ & $0.174(0.010)$ & $0.173(0.010)$ & $0.175(0.015)$ & ns \\
\hline$\$ y(m)$ & $0.045(0.004)$ & $0.044(0.003)$ & $0.042(0.002)$ & $0.040(0.006)^{*}$ & 0.025 \\
\hline 5 (deg) & $29.8(1.3)$ & $30.6(0.8)$ & $30.7(1.0)$ & $31.2(1.3)^{*}$ & 0.031 \\
\hline \multicolumn{6}{|l|}{ Spatiotemporal parameters } \\
\hline$t_{c}(\mathrm{~s})$ & $0.182(0.009)$ & $0.187(0.006)$ & $0.187(0.007)$ & $0.190(0.007)^{*}$ & 0.031 \\
\hline$t_{a}(\mathrm{~s})$ & $0.144(0.013)$ & $0.140(0.013)$ & $0.135(0.011)^{*}$ & $0.132(0.010)^{* *} \dagger$ & 0.010 \\
\hline$f_{\text {step }}(\mathrm{Hz})$ & $3.07(0.11)$ & $3.06(0.09)$ & $3.10(0.07)$ & $3.11(0.05)^{*} \dagger$ & 0.048 \\
\hline$L_{\text {step }}(\mathrm{m})$ & $1.65(0.12)$ & $1.64(0.13)$ & $1.63(0.13)$ & $1.61(0.13)^{* *} \dagger$ & 0.001 \\
\hline$>$ (deg) & $7.0(0.8)$ & $6.5(0.8)$ & $6.2(0.6)^{*}$ & $5.7(0.8)^{* * *} \dagger$ & G0.001 \\
\hline \multicolumn{6}{|c|}{ Horizontal dynamic parameters } \\
\hline$F_{y \min }(\mathrm{N})$ & j431 (125) & j432 (139) & j416 (111) & j413 (99) & ns \\
\hline$B_{\text {imp }}(\mathrm{NIs})$ & j14.93 (2.09) & j15.37 (2.63) & j14.96 (2.39) & j14.77 (2.10) & ns \\
\hline$F_{y \max }(\mathrm{N})$ & $283.9(46.6)$ & 277.5 (47.9) & $267.8(44.0)^{* *}$ & $261.9(38.8)^{* * *} \dagger \dagger$ & 0.001 \\
\hline$P_{\text {imp }}$ (NIs) & $15.05(2.03)$ & $15.44(2.61)$ & $15.02(2.38)$ & $14.85(2.12)$ & ns \\
\hline \multicolumn{6}{|l|}{ Energy parameters } \\
\hline$\dot{\mathrm{V}}_{2}\left(\mathrm{mLIkg}{ }^{\mathrm{j} 1} \mathrm{Imin}^{\mathrm{j} 1}\right)$ & - & $65.1(3.9)$ & $65.4(4.6)$ & $63.6(4.1)$ & ns \\
\hline$C_{r}\left(\mathrm{JIkg}^{\mathrm{j} 1} \mathrm{Im}^{\mathrm{j} 1}\right)$ & - & $4,57(0.28)$ & $4.56(0.25)$ & $4.46(0.33)$ & ns \\
\hline
\end{tabular}

Evolution of spatiotemporal parameters (contact time $\left(t_{c}\right)$, aerial time $\left(t_{a}\right)$, step frequecy $\left(f_{\text {step }}\right)$, step length $\left(L_{\text {step }}\right)$, and angle of velocity vector at toe off $\left.(>)\right)$ and horizontal dynamic parameters (minimal horizontal component of the reaction force $\left(F_{y m i n}\right)$, braking impulse $\left(B_{\text {imp }}\right)$, maximal horizontal component of the reaction force $\left(F_{y \text { max }}\right)$, and propulsive impulse $\left.\left(P_{\text {imp }}\right)\right)$ at one-third $(33 \%)$, at two-thirds $(67 \%)$, and at the end $(100 \%)$ of the time to exhaustion. Data were normalized and expressed as percent of the values obtained at $10 \%$ of the time to exhaustion. ns, not significant.

$* P \mathrm{G} 0.05, * * P \mathrm{G} 0.01$, and $* * * P \mathrm{G} 0.001$, significantly different from the values obtained at $10 \%$ of the time to exhaustion.

$\dagger P \mathrm{G} 0.05$ and $\dagger \uparrow P \mathrm{G} 0.01$, significantly different from the values obtained at $33 \%$ of the time to exhaustion. 
TABLE 2. Correlations between spatiotemporal or horizontal dynamic parameters and stiffness parameters.

\begin{tabular}{|c|c|c|c|c|c|c|c|c|c|}
\hline & \multicolumn{3}{|c|}{$k_{\operatorname{leg}}$} & \multicolumn{3}{|c|}{$k_{\text {vert }}$} & \multicolumn{3}{|c|}{$F_{z \max }$} \\
\hline & $R$ & $R^{2}$ & $P$ & $R$ & $R^{2}$ & $P$ & $R$ & $R^{2}$ & $P$ \\
\hline \multicolumn{10}{|c|}{ Spatiotemporal parameters } \\
\hline$t_{c}$ & j0.84 & 0.71 & $0.003^{* *}$ & j0.86 & 0.74 & $0.001^{* *}$ & j0.079 & 0.01 & ns \\
\hline$t_{a}$ & 0.81 & 0.66 & $0.005^{* *}$ & 0.85 & 0.72 & $0.001 * *$ & j0.135 & 0.02 & ns \\
\hline$f_{\text {step }}$ & j0.56 & 0.31 & ns & j0.52 & 0.27 & ns & j0.114 & 0.02 & ns \\
\hline$L_{\text {step }}$ & j0.29 & 0.08 & ns & jo.192 & 0.04 & ns & j0.488 & 0.24 & ns \\
\hline$>$ & 0.05 & 0.00 & ns & 0.154 & 0.02 & ns & 0.857 & 0.74 & $0.002 * *$ \\
\hline \multicolumn{10}{|c|}{ Horizontal dynamic parameters } \\
\hline$F_{y \min }$ & j0.03 & 0.00 & ns & 0.07 & 0.01 & ns & j0.08 & 0.01 & ns \\
\hline$B_{\text {imp }}$ & j0.55 & 0.30 & ns & j0.46 & 0.21 & ns & j0.43 & 0.18 & ns \\
\hline$F_{y \max }$ & 0.69 & 0.47 & $0.038^{*}$ & 0.67 & 0.45 & $0.048^{*}$ & 0.06 & 0.00 & ns \\
\hline$P_{\mathrm{imp}}$ & j0.60 & 0.36 & ns & j0.48 & 0.23 & ns & j0.12 & 0.01 & ns \\
\hline
\end{tabular}

Correlations between normalized changes (\%) ofi) spatiotemporal parameters (contact time $\left(t_{c}\right)$, aerial time $\left(t_{a}\right)$, step frequecy $\left(f_{\text {step }}\right)$, step length $\left(L_{\text {step }}\right)$, and angle of velocity vector at toe off $(>)$ ) or ii) horizontal dynamic parameters (minimal horizontal component of the reaction force $\left(F_{\text {ymin }}\right)$, braking impulse $\left(B_{\text {imp }}\right)$, maximal horizontal component of the reaction force $\left(F_{\text {ymax }}\right)$, and propulsive impulse $\left.\left(P_{\text {imp }}\right)\right)$ and normalized changes $(\%)$ of leg stiffness $\left(k_{\text {leg }}\right)$, vertical stiffness $\left(k_{\text {vert }}\right)$, and vertical component of reaction force $\left(F_{z \text { max }}\right)$. For every parameter, changes were calculated between $10 \%$ and $100 \%$ of the time to exhaustion. Values significantly related at $* P$ G 0.05 and $* * P G 0.01$.

When the results were normalized with respect to the values measured at $33 \%$ of the time to exhaustion, no significant correlation was observed between either stiffness or $C_{r}$ at the end of the constant velocity run $(100 \%$ of the time to exhaustion). However, between the $33 \%$ and $66 \%$ interval of the time to exhaustion, normalized changes of both $k_{\text {leg }}$ and $k_{\text {vert }}$ were found to be correlated with the normalized changes of $C_{r}(R=\mathrm{j} 0.91, P$ G 0.001 and $R=\mathrm{j} 0.71, P \mathrm{G} \mathrm{0.05}$, respectively) (Fig. 3D). Normalized changes in both $k_{\operatorname{leg}}$ and $k_{\text {vert }}$ were not correlated with the time to exhaustion $(R=0.02, P=0.96$ and $R=0.17$, $P=0.68$, respectively). Moreover, the normalized changes of $C_{r}$ at the $33 \%-66 \%$ interval of the time to exhaustion were negatively correlated with the change in $F_{z \max }$ $(R=\mathrm{j} 0.86, P=0.001)$ and positively correlated with the changes in $\$ L(R=0.67, P \mathrm{G} 0.05)$. Absolute and normal-
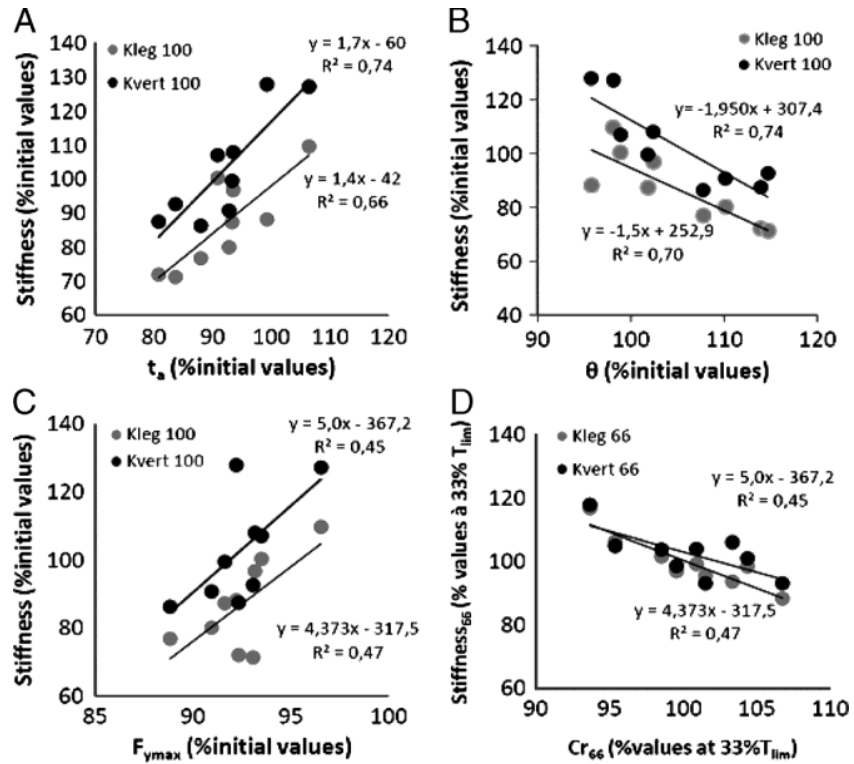

FIGURE 3-Scatterplots with correlations between normalized changes in $k_{\text {leg }}$ and $k_{\text {vert }}$ stiffness and normalized changes in (A) aerial time $\left(t_{a}\right),(\mathrm{B})$ angle of the spring leg at touchdown (5), (C) maximal horizontal reaction force $\left(F_{\text {ymax }}\right)$, and $(D)$ energy cost of running $\left(C_{r}\right)$. Changes were calculated between $10 \%$ and $100 \%$ of the time to exhaustion, except for $C_{r}$, which was calculated between $33 \%$ and $66 \%$ of the time to exhaustion. ized values of oxygen uptake and cost of running are presented in Table 1.

\section{DISCUSSION}

The first purpose of this study was to characterize in elite triathletes the effect of fatigue in leg-spring behavior during an exhaustive run. Because of the close relationships between running velocity and leg stiffness $(6,27)$, the run was imposed here at a constant pace ( $95 \%$ of $\left.\mathrm{vV} \mathrm{O}_{2 \max }\right)$. One of the main results was that leg stiffness decreased with fatigue. This change in spring - mass behavior agrees with previous sprint (20) or long distance (13) investigations. However, in these studies, the reduced leg stiffness was primarily related with the leg compression increase. On the contrary, the present results reveal that the vertical force is the most associated with the adaptations of leg stiffness, leg compression remaining constant through the fatiguing run.

Regarding the vertical stiffness, no change was observed. This finding differs from the abovementioned studies in which this parameter was reported to decrease with time $(13,16,20,29)$. The discrepancy between these results could be explained by the similar decrease in $\$ y$ and $F_{z \max }$ observed in this study (E10\%). These results are all the same consistent with those reported by Millet et al. (28), who suggested that elite triathletes partly compensate for the effects of fatigue by decreasing the maximal vertical displacement of the COM during foot contact.

It could be assumed that the alteration of the neuromuscular functioning as a result of the fatigue induced by a severe running exercise directly influences the leg-spring behavior. Among the stride mechanical characteristics, the vertical force is the most affected by this stiffness adaptation. This assumption is firstly supported by EMG studies investigating the effect of fatigue during running (31) or jumping exercises $(5,24,34)$. For example, Nummela et al. (31) tested well-trained runners during a self-paced $5-\mathrm{km}$ run. They showed that better performances were observed in runners whose level of muscle recruitment remains stable or just slightly decreases during the 5-km run. In jumping conditions, Kuitunen et al. (24) found that the leg stiffness 
was strongly related to the EMG changes in the lower limb. Although we did not perform EMG analyses, it is consistent to assume that the observed decrease in vertical reaction force was related to the neuromuscular capacity of the lower limbs. Second, it is also supported by the positive relationship between the normalized changes in maximal vertical forces $\left(F_{z \max }\right)$ and the angle of the velocity vector at toe off $(>)$. Interestingly, the subjects who exhibited the highest difficulties in sustaining great vertical force were those who flattened their COM trajectories. Figure 4 provides a schematic of the above-cited modifications of the SMM behavior with fatigue. This figure presents the mean modification in several parameters but does not account for the interindividual variability.

This quite large interindividual variability is partly explained by the different time courses of stiffness changes from on subject to another. For example, although four triathletes presented a decrease in $k_{\text {leg }}$ greater than $10 \%$ after the first third of the time to exhaustion, three subjects presented a decrease less than $10 \%$ after the middle third and two subjects did not show any decrease. Regarding $k_{\text {vert }}$ values, the individual time course was more progressive. Although for seven subjects $k_{\text {vert }}$ fluctuated between T5\% after the first third, only one subject remained in this range of variation at the end of the run. Indeed, four subjects presented an increase whereas four subjects presented a decrease in vertical stiffness, such as these eight subjects presented variations in this parameter higher than $10 \%$ at the end of the run. These great differences of the time course changes between subjects were previously observed for moderated-velocity/long-duration running $(13,22)$. The abovementioned observations show that this is also true for a more severe intensity/shorter duration exhaustive run (Table 1 and Fig. 2).

The analysis of spatiotemporal parameters permits for greater insight into mechanisms described above that

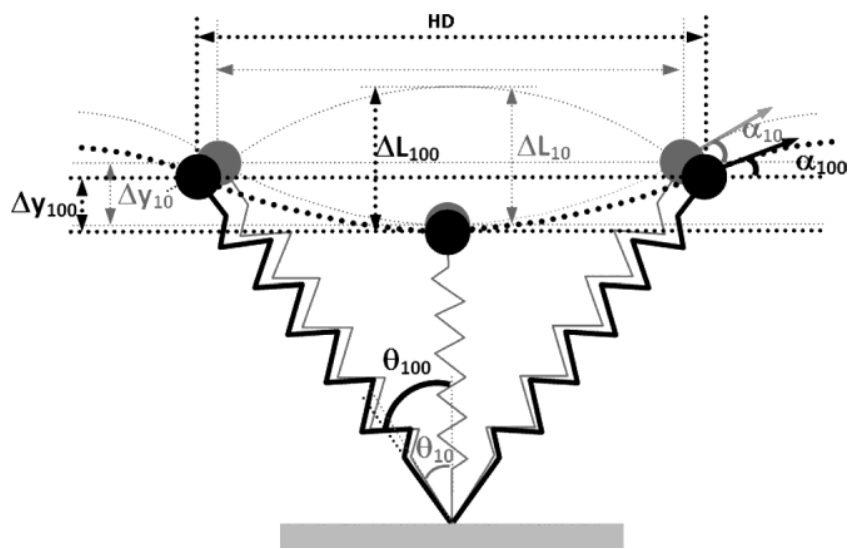

FIGURE 4-Schematic representation of the evolution of the SMM between the beginning ( $10 \%$ of the time to exhaustion, gray) and the end $(100 \%$ of the time to exhaustion, black). $>$, angle of velocity vector at toe off; $\$ L$, leg compression; $\$ y$, vertical displacement of the COM; 5 , angle of the spring leg at touchdown; HD, horizontal distance of the COM during the contact phase. allowed subjects to maintain a constant velocity despite fatigue. At constant velocity, contact time reflects the legspring angle at the moment of impact. Increasing the angle of the lower limb allowed the subjects to increase their horizontal COM distance during the contact phase. Furthermore, it might have allowed for the subject to maintain a constant horizontal impulse despite the decrease in neuromuscular capacity as a result of fatigue. This conclusion is supported by the fact that normalized changes in braking and propulsive impulses were positively correlated with normalized 5 changes; in other words, the subjects who best maintained horizontal impulse were those who increased the most their leg-spring angle at the moment of impact. Moreover, negative relationships were observed between $k_{\text {vert }}$ or $k_{\text {leg }}$ and 5 . Taken together, these results imply that changes of vertical and leg stiffness, via the increase in the leg-spring angle at impact, allow for maintaining the horizontal forces concomitantly with the onset of fatigue. However, it must be noticed that these findings do not take into account the changes in ankle, knee, and hip angles with fatigue. In running as well as in hopping conditions, it was shown that changes in lower limbs kinematics have substantial effects on the global musculoskeletal stiffness $(1,21,27)$. Further studies are required to specifically analyze the contributions of these adaptations with the fatigue induced at this running velocity.

In nonfatigue status, it was shown that leg stiffness is positively related to step frequency (14). However, the present results show that $k_{\text {leg }}$ decreased while $f$ increased. As seen in the Results section, a significant increase in step frequency despite an increase in contact time was due to a greater decrease in aerial time. This result can explain the opposite changes observed between $k_{\operatorname{leg}}$ and $f$. Morin et al. (30) also reported that $k_{\operatorname{leg}}$ was more strongly associates with contact time than with stride frequency. As mentioned earlier, this increase in $t_{c}$ could be due to a reduced capacity of the neuromuscular system to generate force rapidly or to tolerate impact forces (17). By examining subjects on an exhaustive 10-km run, Paavolainen et al. (33) concluded a failure of the muscle stiffness on the basis of i) relationships between the decreased preactivation and horizontal ground reaction forces and ii) longer contact times in the braking phases. It could be noticed that in response to central and/or peripheral physiological failure, beyond the parameters of the stance phase, the stiffness adaptation affects globally the stride characteristics. The present results have indeed shown that normalized changes in stiffness (both $k_{\operatorname{leg}}$ and $k_{\text {vert }}$ ) were strongly correlated not only with increases in contact time but also with decreases in aerial times. This would contribute to maintain a constant velocity in the later stages of the severe intensity exhaustive run.

During nonfatiguing protocols, Farley and González (14) and Morin et al. (30) demonstrated that a leg stiffness adjustment is observed when different foot contact time (30) or stride frequency $(14,30)$ is imposed. Nevertheless, the respective impact of a neuromuscular failure or of a central 
regulatory process on the stiffness adaptation remained unclear under fatiguing conditions. Further investigations are required to identify whether the modifications in legspring stiffness are initially associated with deterioration in the neuromuscular functioning or with an anticipatory adjustment of the stride pattern with respect to the evolution of neuromuscular afferent feedbacks.

The second purpose of this study was to characterize how the changes in leg-spring behavior were related to the cost of running. From an energetic point of view, we observed that during the middle third of the time to exhaustion, the triathletes who presented highest decreases in stiffness values were also those who presented highest increases in $C_{r}$. This observation is in agreement with results obtained by numerous other studies $(10,19,35)$ that showed that runners with greater leg compliance had greater cost of running. Furthermore, negative correlations were also observed between normalized changes in $F_{z \max }$ and oxygen uptake. Our present study suggests that the adaptation of the leg stiffness as a result of fatigue leads to stride characteristics energetically less economical. However, the significant relationships

\section{REFERENCES}

1. Arampatzis A, Brüggemann GP, Metzler V. The effect of speed on leg stiffness and joint kinetics in human running. $J$ Biomech. 1999;32(12):1349 - 53.

2. Belli A, Lacour JR, Komi PV, Candau R, Denis C. Mechanical step variability during treadmill running. Eur J Appl Physiol. 1995; 70(6):510 - 7

3. Bentley DJ, Millet GP, Vleck VE, McNaughton LR. Specific aspects of contemporary triathlon: implications for physiological analysis and performance. Sports Med. 2002;32(6):345 - 59.

4. Blickhan R. The spring-mass model for running and hopping. J Biomech. 1989;22(11 - 12):1217 - 27.

5. Bonnard M, Sirin AV, Oddsson L, Thorstensson A. Different strategies to compensate for the effects of fatigue revealed by neuromuscular adaptation processes in humans. Neurosci Lett. 1994;166(1):101 - 5.

6. Brughelli M, Cronin J. Influence of running velocity on vertical, leg and joint stiffness: modelling and recommendations for future research. Sports Med. 2008;38(8):647 - 57.

7. Candau R, Belli A, Millet GY, Georges D, Barbier B, Rouillon JD. Energy cost and running mechanics during a treadmill run to voluntary exhaustion in humans. Eur J Appl Physiol Occup Physiol. 1998;77(6):479 - 85.

8. Cavagna GA. Force platforms as ergometers. J Appl Physiol. 1975; 39(1):174 - 9 .

9. Chapman AR, Vicenzino B, Blanch P, Dowlan S, Hodges PW. Does cycling effect motor coordination of the leg during running in elite triathletes? J Sci Med Sport. 2008;11(4):371 - 80.

10. Dalleau G, Belli A, Bourdin M, Lacour JR. The spring-mass model and the energy cost of treadmill running. Eur J Appl Physiol Occup Physiol. 1998;77(3):257 - 63.

11. Delextrat A, Tricot V, Bernard T, Vercruyssen F, Hausswirth C, Brisswalter J. Drafting during swimming improves efficiency during subsequent cycling. Med Sci Sports Exerc. 2003;35(9): $1612-9$.

12. Delextrat A, Tricot V, Bernard T, Vercruyssen F, Hausswirth C, Brisswalter J. Modification of cycling biomechanics during a swim-to-cycle trial. J Appl Biomech. 2005;21(3):297 - 308.

13. Dutto DJ, Smith GA. Changes in spring-mass characteristics dur- between $k_{\text {leg }}, k_{\text {vert }}$, and $C_{r}$ between one-third and two-thirds of the run were found to not influence the subject' $s$ time to exhaustion.

In conclusion, the decrease in leg-spring stiffness during a severe intensity exhaustive run affects primarily the decrease in vertical force. The decrease in the velocity vector angle at takeoff allowed the subject to flatten the trajectory of the center of mass. The increase in the leg-spring angle at the moment of impact allowed the subject to maintain constant horizontal impulse, which contributed to the maintenance of constant velocity during later stages of the run. However, from an energetic point of view, runners with greatest increases of cost of running were those with greatest changes of stiffness as they fatigued during the run to exhaustion.

This study was financed by the French Ministery of Health and Sports.

The authors gratefully acknowledge the French Triathlon Federation. They thank Yann Le Meur for his reading and comments.

The results of the present study do not constitute endorsement by the American College of Sports Medicine. ing treadmill running to exhaustion. Med Sci Sports Exerc. 2002; 34(8): $1324-31$.

14. Farley CT, González O. Leg stiffness and stride frequency in human running. J Biomech. 1996;29(2):181 - 6.

15. Gaesser GA, Poole DC. The slow component of oxygen uptake kinetics in humans. Exerc Sport Sci Rev. 1996;24:35 - 71.

16. Girard O, Millet G, Slawinski J, Racinais S, Micallef P. Changes in leg-spring behavior during a $5000 \mathrm{~m}$ self-paced run in differently trained athletes. Sci Sports. 2010;25(2):99 - 102.

17. Gollhofer A, Komi PV, Miyashita M, Aura O. Fatigue during stretch-shortening cycle exercises: changes in mechanical performance of human skeletal muscle. Int J Sports Med. 1987;8(2):71 - 8.

18. Hausswirth C, Brisswalter J. Strategies for improving performance in long duration events: Olympic distance triathlon. Sports Med. 2008;38(11):881 - 91.

19. Heise GD, Martin PE. Leg-spring characteristics and the aerobic demand of running. Med Sci Sports Exerc. 1998;30(5):750 - 4.

20. Hobara $\mathrm{H}$, Inoue $\mathrm{K}$, Gomi $\mathrm{K}$, et al. Continuous change in springmass characteristics during a $400 \mathrm{~m}$ sprint. J Sci Med Sport. 2010; 13(2):256 - 61.

21. Hobara H, Inoue K, Muraoka T, Omuro K, Sakamoto M, Kanosue K. Leg stiffness adjustment for a range of hopping frequencies in humans. $J$ Biomech. 2010;43(3):506 - 11.

22. Hunter I, Smith GA. Preferred and optimal stride frequency, stiffness and economy: changes with fatigue during a 1-h highintensity run. Eur J Appl Physiol. 2007;100(6):653 - 61.

23. Kerdok AE, Biewener AA, McMahon TA, Weyand PG, Herr HM. Energetics and mechanics of human running on surfaces of different stiffnesses. J Appl Physiol. 2002;92(2):469 - 78.

24. Kuitunen S, Kyröläinen H, Avela J, Komi PV. Leg stiffness modulation during exhaustive stretch-shortening cycle exercise. Scand J Med Sci Sports. 2007;17(1):67 - 75.

25. Kyröläinen H, Pullinen T, Candau R, Avela J, Huttunen P, Komi PV. Effects of marathon running on running economy and kinematics. Eur J Appl Physiol. 2000;82(4):297 - 304.

26. Laursen PB, Rhodes EC, Langill RH. The effects of 3000-m swimming on subsequent 3-h cycling performance: implications for ultraendurance triathletes. EurJ Appl Physiol.2000;83(1):28 - 33. 
27. McMahon TA, Cheng GC. The mechanics of running: how does stiffness couple with speed? J Biomech. 1990;1(1):65 - 78.

28. Millet GP, Millet GY, Hofmann MD, Candau RB. Alterations in running economy and mechanics after maximal cycling in triathletes: influence of performance level. Int J Sports Med. 2000;21(2):127 - 32.

29. Morin JB, Jeannin T, Chevallier B, Belli A. Spring-mass model characteristics during sprint running: correlation with performance and fatigue-induced changes. Int J Sports Med. 2006;27(2):158 - 65.

30. Morin JB, Samozino P, Zameziati K, Belli A. Effects of altered stride frequency and contact time on leg-spring behavior in human running. J Biomech. 2007;40(15):3341 - 8.

31. Nummela AT, Paavolainen LM, Sharwood KA, Lambert MI, Noakes TD, Rusko HK. Neuromuscular factors determining $5 \mathrm{~km}$ running performance and running economy in well-trained athletes. Eur J Appl Physiol. 2006;97(1):1 - 8.

32. Deleted in proof.
33. Paavolainen L, Nummela A, Rusko H, Häkkinen K. Neuromuscular characteristics and fatigue during $10 \mathrm{~km}$ running. Int J Sports Med.1999;20(8):516 - 21.

34. Padua DA, Arnold BL, Perrin DH, Gansneder BM, Carcia CR, Granata KP. Fatigue, vertical leg stiffness, and stiffness control strategies in males and females. J Athl Train. 2006;41(3):294 - 304.

35. Slawinski J, Billat V. Changes in internal mechanical cost during overground running to exhaustion. Med Sci Sports Exerc. 2005; 37(7): $1180-6$.

36. Slawinski J, Heubert R, Quievre J, Billat V, Hanon C. Changes in spring-mass model parameters and energy cost during track running to exhaustion. J Strength Cond Res. 2008;22(3):930 - 6.

37. Deleted in proof.

38. Vleck VE, Bentley DJ, Millet GP, Bürgi A. Pacing during an elite Olympic distance triathlon: comparison between male and female competitors. J Sci Med Sport. 2008;11(4):424 - 32. 